\title{
Vocal associations to individual letters
}

HAROLD J. VETTER

UNIVERSITY OF MARYLAND

Vocal associations to each of the letters of the alphabet were elicited from 2 groups of $70 \mathrm{Ss}$ under procedures of discrete and continuous response. Results were compared with data reported by Anderson (1965) on written associations to upper- and lower-case letters. Despite some differences in the number of associations given under visual and vocal modes of stimulus presentation, the pattern of response frequency in the two conditions was similar. A further comparison revealed only minor differences between written and vocal associations in terms of initial response to continuous association procedures. The relevance of these findings for psycholinguistic and verbal leaming studies was noted.

Research by Anderson (1965) has supplied data for word associations to individual letters of the alphabet. Following procedures devised by Noble (1952), Anderson elicited both discrete and continuous written associations to upper- and lower-case stimulus letters. Examination of the most frequent associations indicated a high degree of consistency among the common associations for the single and continued instructional procedures and upper- and lower-case presentations of the individual letters. In addition, using data reported by several previous investigators, Anderson demonstrated a significant relationship between $\mathrm{m}$ values and frequency of letters (Bourne \& Ford, 1961), vocal reaction times to letters (Fitts \& Switzer, 1962), and preferences for individual letters (Horton \& Mecherikoff, 1960).

Since many studies of verbal learning and verbal behavior rely on vocal rather than visual modes of stimulus presentation, it seemed important to extend research along this additional dimension. Of particular Interest and concern were the potential effects of phonetic properties of the stimulus letters on the number and variety of associations elicited. Accordingly, the following study was designed to gather data on vocal associations to individual letters of the alphabet under conditions of discrete and continuous association. Method

An initial group of $70 \mathrm{Ss}$ recruited from introductory psychology classes at the University of Maryland during the summer of 1966 was exposed to different random orders of the 26 letters of the alphabet. Stimulus materials were provided by Hintzman's (1966) list of 100 random permutations of letters. Each $S$ was given one letter at a time and instructed to respond with the first word that occurred to him. Interstimulus intervals of 2-3 sec. were used and there were rest periods of $2 \mathrm{~min}$. each at the end of the 8 th and 17th letters. Both stimuli and responses were vocal and the sessions were tape recorded.
A second group of 70 Ss was obtained from introductory psychology classes at the University of Maryland during the fall of 1966. These Ss were also exposed to differing random orders of the letters of the alphabet (Hintzman, 1966). Instead of discrete associations, however, Ss were given one letter at a time and instructed to respond with as many words as they could think of which started with the stimulus letter. Response periods of $60 \mathrm{sec}$. to each letter and inter-stimulus intervals of 2-3 sec. were used. Ss were given rest periods of $2 \mathrm{~min}$. each at the end of the 8 th and 17 th letters. As in the procedure for discrete associations, sessions were tape recorded.

\section{Results and Discussion}

Means and SDs for the number of continued associations are presented in Table 1 . Vocal $\mathrm{m}$ constitutes the mean number of vocal responses given by all Ss in a 60-sec. period. Vocal $\mathrm{m}$ values range from a high of 16.9 for the letter $\mathrm{S}$ to 1.8 for the letter $\mathrm{X}$. The SDs are comparable in size to those reported by Noble (1952) for disyllable words and by Anderson (1965) for written associations to letters.

Letters were ranked in order of frequency of associations and comparisons were made between vocal $\mathrm{m}$ and

Table 1.

Average Number of Associations (Continually for $60 \mathrm{Sec}$ ) To Letters

\begin{tabular}{ccc} 
S-Letter & Vocal m & SD \\
\hline A & 13.8 & 3.1 \\
B & 15.2 & 3.5 \\
C & 14.1 & 3.6 \\
D & 14.4 & 3.2 \\
E & 10.9 & 3.1 \\
F & 14.3 & 3.8 \\
G & 13.1 & 2.8 \\
H & 14.1 & 3.5 \\
I & 11.1 & 3.0 \\
J & 10.0 & 3.1 \\
K & 6.3 & 3.0 \\
L & 14.3 & 3.8 \\
M & 14.8 & 3.5 \\
N & 11.0 & 3.3 \\
O & 9.1 & 3.1 \\
P & 14.3 & 4.0 \\
Q & 8.1 & 3.4 \\
$R$ & 13.9 & 3.5 \\
S & 16.9 & 4.3 \\
T & 14.8 & 4.1 \\
U & 7.3 & 2.9 \\
V & 8.9 & 3.3 \\
W & 14.2 & 3.7 \\
$X$ & 1.8 & 1.6 \\
Y & 6.7 & 2.2 \\
Z & 4.7 & 1.8 \\
\hline & &
\end{tabular}


Table 2. Most Frequent Common Associations to Letters

\begin{tabular}{|c|c|c|c|c|}
\hline \multirow[b]{2}{*}{ S.Letter } & \multicolumn{2}{|c|}{$\begin{array}{l}\text { Single As sociations } \\
\qquad(N=70)\end{array}$} & \multicolumn{2}{|c|}{$\begin{array}{l}\text { First Response Continued } \\
\text { Associations }(\mathrm{N}=70)\end{array}$} \\
\hline & Association & n & Association & $n$ \\
\hline $\begin{array}{l}\text { A } \\
\text { B }\end{array}$ & $\begin{array}{l}\text { apple } \\
\text { boy }\end{array}$ & $\begin{array}{l}20 \\
12\end{array}$ & $\begin{array}{l}\text { apple } \\
\text { boy }\end{array}$ & $\begin{array}{l}27 \\
16\end{array}$ \\
\hline $\mathrm{C}$ & cat & 24 & cot & 31 \\
\hline D & $\operatorname{dog}$ & 30 & $\operatorname{dog}$ & 35 \\
\hline$E$ & every & 14 & eat & 11 \\
\hline$F$ & Frank & 8 & Frank & 6 \\
\hline G & good & 8 & go $($ good 11$)$ & 13 \\
\hline $\mathrm{H}$ & help & 6 & house (help 6) & 7 \\
\hline 1 & in & 16 & in & 11 \\
\hline$J$ & Jack & 6 & Jack & 8 \\
\hline $\mathrm{K}$ & know & 8 & keep & 6 \\
\hline$L$ & love & 18 & love & 12 \\
\hline$M$ & mother & 10 & man (money 6 , mother 6 ) & 7 \\
\hline $\mathbf{N}$ & no (never 8 ) & 8 & no & 12 \\
\hline 0 & only & 6 & open & 16 \\
\hline $\mathbf{P}$ & pea & 6 & people & 8 \\
\hline$Q$ & quiet & 10 & queen (quick 12) & 14 \\
\hline $\mathbf{R}$ & red (read) & 10 & $\operatorname{rat}(\operatorname{run} 6, \operatorname{red} 6)$ & 7 \\
\hline$S$ & sleep & 6 & stop & 8 \\
\hline$T$ & Tom & 6 & time & 6 \\
\hline $\mathrm{U}$ & use & 6 & under & 15 \\
\hline$\checkmark$ & very (vary) & 18 & very (vary) & 18 \\
\hline$w$ & was (win 6) & 6 & woter & 8 \\
\hline$x$ & xylophone & 30 & xylophone & 48 \\
\hline$Y$ & you & 26 & you & 24 \\
\hline Z & zebra & 18 & zebra & 28 \\
\hline
\end{tabular}

m values reported for continued associations to upperand lower-case letters by Anderson (1965). The rankorder correlation (rho) between vocal m and upper-case m was .94; the rank-order correlation (rho) between vocal $\mathrm{m}$ and lower-case $\mathrm{m}$ was .90 . Thus, despite differences in the number of associations given under written and vocal modes of stimulus presentation, there is a good deal of similarity between the two tasks in terms of the pattern of response frequency.

However, a few exceptions to this finding must be noted. With letters $X$ and $Z$, there were substantial differences in response frequency to the printed stimulus letters in Anderson's (1965) study and the vocally presented letters in the present investigation. Anderson reported a mean of 9.5 for $\mathrm{X}$ and a mean of 9.0 for $\mathrm{Z}$, as compared with means of $1.8(\mathrm{X})$ and $4.7(\mathrm{Z})$ in the present study. These findings suggest that the cue properties of the printed stimulus letter are of greater relative significance in instances where the potential response range is constricted by factors of lexical frequency (Thorndike \& Lorge, 1944) than in other cases with a less limited repertory of potential associations.

The most frequent associations given to each letter are presented in Table 2, together with $N$, the number of Ss in each series giving the most common associations. Words such as "red" and "very" are accompanied by the homophones "read" and "vary." Other words in parentheses followed by numbers represent associations which were given equally or almost equally often. Data for the continued associations are taken from the first response to each letter.

In addition to the rather high degree of consistency noted between the discrete and continuous vocal associations, a comparison with Anderson's (1965) data reveals only minor differences in initial associations between written and vocal modes of presentation. In some cases Anderson's Ss gave an association to a particular letter which ranked second in frequency in the vocal group, or vice versa. In general, however, there is a close resemblance between the two lists (vocal and written associations) and between the discrete and continuous associations.

Vocal associations generally began with the same phoneme as that represented by the stimulus letter. Examples are: "cocoon" for $\mathrm{K}$, "hour" for $O$, "cute" for $Q$, and "excerpt" for $X$. The strong phonetic influence is further seen in cases where the response began with the stimulus letter, such as "people" for $P$ instead of "pneumonia," and "tea" for $T$ instead of "though" as reported by Anderson (1965).

The close correspondence between associations to vocally and visually presented stimulus letters is a finding that has relevance and significance for psycholinguistic and verbal learning studies. To the extent that $m$ and vocal $m$ values are closely related, one might infer a comparable interrelationship between vocal $\mathrm{m}$ and measures of frequency of occurrence of letters in the language, measures of preferences for letters, and vocal reaction time to letters.

\section{References}

Anderson, N. S. Word associations to individual letters. J. verbal Learn. verbal Behav., 1965, 4, 541-545.

Boume, C. P., \& Ford, D. F. A study of the statistics of letters in English words. Inform. Control, 1961, 4, 48-67.

Fitts, P. M., \& Switzer, G. Cognitive aspects of information pro cessing. J. exp. Psychol., 1962, 63, 321-329.

Hintzman, D. L. Tables of random letters. Psychon. Sci., 1966, 5, 253-254.

Horton, D. L., \& Mecherikoff, M. Letter preferences, J. appl. Psychol., 1960, 44, 252-253.

Noble, C. E. An analysis of meaning. Psychol. Rev., 1952, 421430.

Thomdike, E. L., \& Lorge, I. The teacher's word book of 30,000 words. New York: Columbia University Press, 1944.

Underwood, B. J., \& Schulz, R. W. Meaningfulness and verbal learning. Philadelphia: Lippincott, 1960. 